\title{
Longitudinal Asymptomatic Xanthonychia
}

\author{
Guillermo Antonio Guerrero-González ${ }^{\mathrm{a}} \quad$ Juan Carlos Robles-Mendez ${ }^{\mathrm{a}}$ \\ Marcela Saeb-Limab Nilton Gioia Di Chiacchioc ${ }^{\mathrm{c}}$ Osvaldo Vázquez-Martínez ${ }^{\mathrm{a}}$ \\ Jorge Ocampo-Candiani ${ }^{a}$ \\ a Dermatology Department, Hospital Universitario "Dr. José Eleuterio González," Monterrey, and bathology \\ Department, Instituto Nacional de Ciencias Médicas y Nutrición Salvador Zubirán, Mexico City, Mexico; ${ }^{\circ}$ Dermatology \\ Department, Hospital do Servidor Publico Municipal de São Paulo, São Paulo, Brazil
}

\section{Question}

\section{Clinical Presentation}

A 53-year-old man presented with a 2-year history of an asymptomatic fingernail dystrophy. There was no history of trauma. Upon clinical examination, the left first fingernail had a partial longitudinal, thickened, yellowish plate (Fig. 1).

\section{Dermoscopic Appearance}

Dermoscopic examination revealed a longitudinal band of xanthonychia with splinter hemorrhages involving the proximal and distal nail plate, longitudinal parallel white lines, and thickening of the free edge along with multiple cavities at the distal nail plate margin (Fig. 2).

What is your diagnosis?

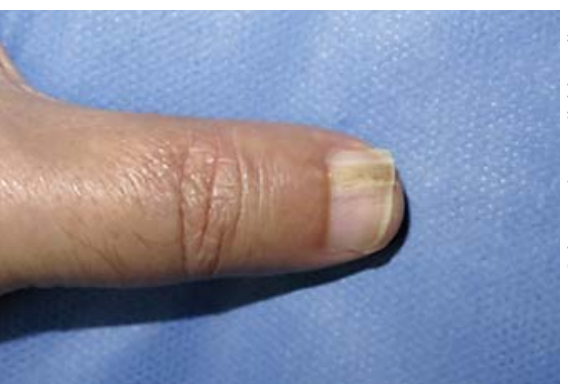

Fig. 1. Clinical presentation. Thickened, yellowish plate.
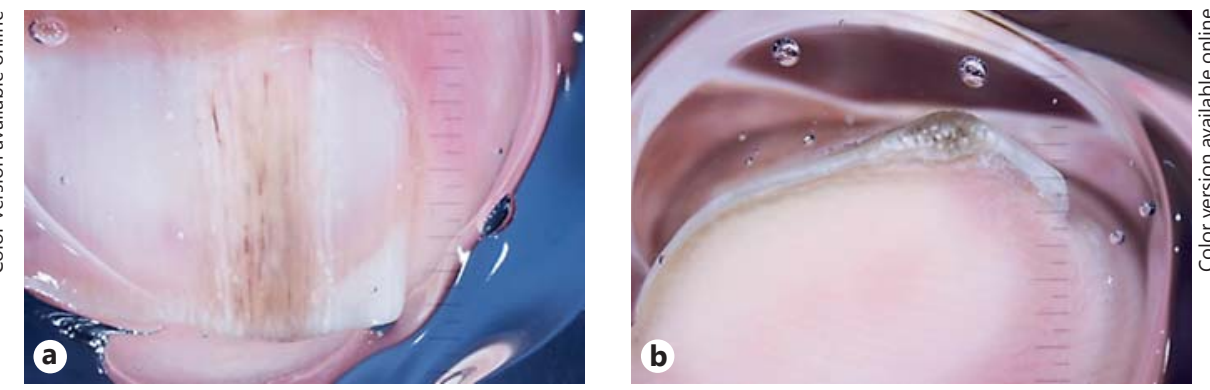

Fig. 2. a Dermoscopy showing proximal and distal splinter hemorrhages within the band of xanthonychia, along with longitudinal parallel white lines. b Thickened free edge with multiple cavities.

Work was conducted at all three centers mentioned.

\section{KARGER}

(C) 2017 S. Karger AG, Basel

E-Mail karger@karger.com

www.karger.com/sad
Jorge Ocampo-Candiani

Dermatology Department, Hospital Universitario "Dr. José Eleuterio González" Francisco I. Madero pte. y Av. Gonzalitos s/n Col. Mitras Centro Monterrey 64460 (Mexico)

E-Mail jocampo2000@yahoo.com.mx 


\section{Answer}

\section{Onychomatricoma}

Histologic Diagnosis. Subungual exploration revealed a villous tumor in the nail matrix (Fig. 3). A shave biopsy showed a tumor composed of epithelial cell strands that vertically penetrated into a fibrotic dermis and appeared to be lined with optical cavities (Fig. 4). This confirmed the diagnosis of an onychomatricoma.

Key Message. The presence of longitudinal thickening and xanthonychia should always raise suspicion of an onychomatricoma. Splinter hemorrhages and holes in the distal margin of the nail plate are other common clinical features. Dermoscopy provides criteria that are less subject to misinterpretation. Nail clipping is a simple, noninvasive diagnostic tool in case of doubt. Dermatologists should be familiar with this benign tumor to avoid delaying diagnosis $[1,2]$.

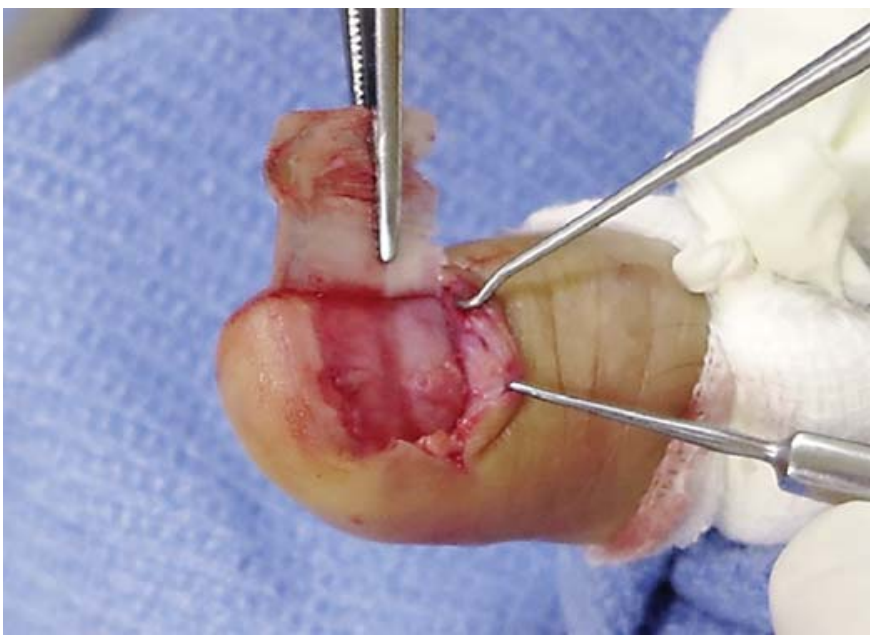

Fig. 3. Villous tumor originating from the nail matrix.

\section{Statement of Ethics}

Patient's identity was protected in the manuscript and written permission for photograph use was signed by the patient.

\section{Disclosure Statement}

The authors have no conflicts of interest to disclose.

\section{Keywords}

Onychomatricoma $\cdot$ Nail tumors $\cdot$ Nail pathology . Nail surgery

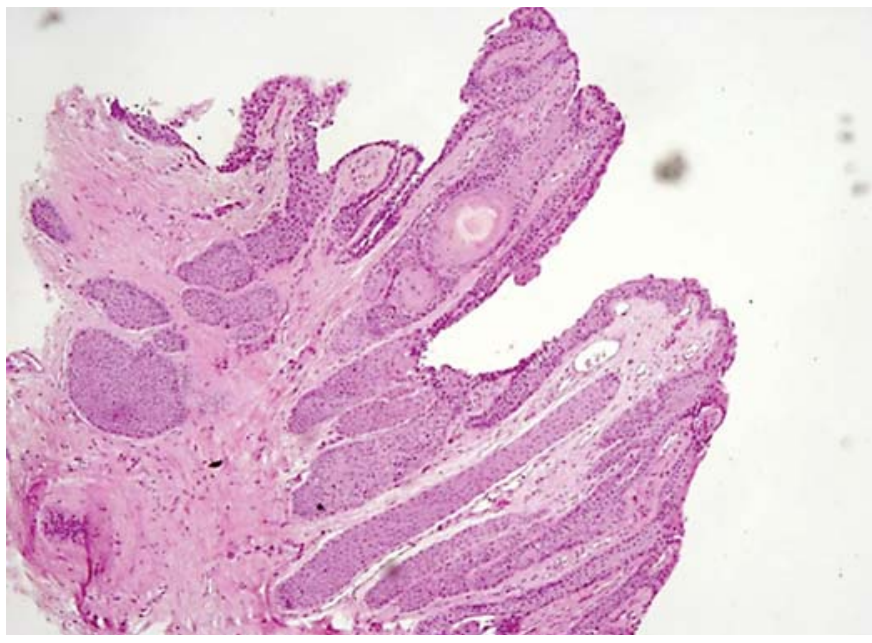

Fig. 4. Histopathological findings of onychomatricoma: strands of epithelial cells originating from the nail matrix that penetrate into the fibrotic stroma, the strands appear to be lined with optically clear cavities (hematoxylin-eosin stain; original magnification, $\times 5$ ).

\section{References}

1 Di Chiacchio N, Tavares GT, Tosti A, Di Chiacchio NG, Di Santis E, Alvarenga L, et al: Onychomatricoma: epidemiological and clinical findings in a large series of 30 cases. Br J Dermatol 2015;173:1305-1307.
2 Lesort C, Debarbieux S, Duru G, Dalle S, Poulhalon N, Thomas L: Dermoscopic features of onychomatricoma: a study of 34 cases. Dermatology 2015;231:177-183. 